\title{
STUDI DAN PENCIPTAAN MOTIF NITIK DI SENTRA BATIK KEMBANGSONGO BANTUL
}

\author{
I Made Sukanadi \\ Sugeng Wardoyo *)
}

\begin{abstract}
This study was conducted in the Batic Center in Kembangsongo in Desa Jetis, Trimulyo, Bantul. This center is known for its specific dotted motif which is popularly known as batik Nitik. The life of batik is dynamic. Currently, batik users have started to keep up with the contemporary batik and give up batik with Nitik motif as the unique characteristic of batik Bantul. Consumers of painted batik see the dot motif of batik has been out of date and monotonous. It lacks innovation in design, shape, motive, and color.

Innovation in the motif of batik Nitik has to be performed. Studies on Nitik motifs are needed to collect the data for further evaluation. New motifs are needed to meet consumers' interest. The motifs of Nitik have to be preserved. The obstacles that the artisans in Kembangsongo have include the meeting of consumers' need for new motifs and designs. The artisans have no competence to create new designs due to their limited knowledge in design and innovation in batik Nitik.

This study is expected to overcome the problem that the artisans face up. The new designs or motifs will have to preserve the specificity. Therefore, the artisans will be more creative and innovative in anticipating the market to meet consumers' preference. It is expected that batik artisans of in the batik center in Kembangsongo, Trimulyo, Jetis, Bantul will have better economic prosperity.
\end{abstract}

Keywords: batik Nitik, artisans, motif, consumers, Kembangsongo

\section{ABSTRAK}

Penelitian ini dilakukan di Kembangsongo yang merupakan sentra batik tulis terletak di Desa Jetis, Trimulyo, Bantul. Sentra ini terkenal dengan hasil batik tulis yang memiliki cirri khas motif titik-titik yang dikenal sebagai batik Nitik. Perjalanan batik tulis mengalami pasang surut dimana kepeduliaan masyarakat pengguna batik tulis Nitik yang sudah mulai mengikuti selera pasar dan seolah bergerak meninggalkan batik bermotif Nitik sebagai salah satu ciri khas batik Bantul. Konsumen batik tulis menilai bahwa motif batik Nitik sudah ketinggalan jaman dan terkesan monoton karena kurangnya inovasi desain, baik bentuk, motif, dan pewarnaannya.

Pengembangan motif batik Nitik mutlak dilakukan, dengan cara studi melalui penelitian motif-motif Nitik, kemudian didata, dilakukan evaluasi, dan dilakukan penciptaan motif-motif baru sesuai selera konsumen dengan tetap mempertahankan motif batik Nitik sebagai warna lokal yang harus tetap dilestarikan. Kendala para pengrajin batik di sentra Kembangsongo adalah memenuhi pesanan konsumen yang menginginkan desain motif-motif baru. Pengrajin tidak memiliki kemampuan untuk menciptakan desain baru karena keterbatasan pengetahuan desain dan inovasi bentuk batik Nitik.

\footnotetext{
* I Made Sukanadi dan Sugeng Wardoyo, Staf Pengajar Program Studi Kriya Seni, Jurusan Kriya, Fakultas Seni Rupa, Institut Seni Indonesia Yogyakarta.
} 
Penelitian ini diharapkan mampu membantu mengatasi masalah pengrajin, batik dalam menciptakan desain atau motif batik Nitik baru yang tetap memiliki ciri khas, sehingga tercipta masyarakat kreatif dan inovatif dalam menghadapi pasar dan mampu memenuhi keinginan konsumen. Dari kegiatan ini akan meningkatkan kesejahteraan ekonomi pengrajin batik di sentra Kembangsongo, Jetis, Trimulyo, Bantul.

Kata kunci: batik Nitik, pengrajin, motif, konsumen, Kembangsongo

\section{PENDAHULUAN}

Kembangsongo merupakan sentra batik tulis yang terletak di Desa Jetis, Trimulyo, Bantul yang memiliki ciri khas motif batik yang disebut batik Nitik. Motif ini terdiri dari unsur titik-titik besar dan kecil membentuk suatu pola-pola geometris, bentuk-bentuk bunga, daun, sulur, dan garis-garis panjang. Motif batik Nitik ini sekarang dipandang oleh konsumen batik tulis terkesan monoton dan miskin inovasi bentuk dan hasil pewarnaan yang hanya berwarna biru wedel sogan coklat.

Batik motif Nitik yang dibuat oleh pengrajin di sentra batik Kembangsongo, merupakan salah satu motif kekayaan batik Bantul, yang mendukung kegiatan ekonomi kreatif kemasyarakatan. Dari kegiatan membatik yang dilakukan di sentra ini, telah melibatkan kaum ibu-ibu yang menjanjikan sebagai kegiatan industri yang menjadi lapangan pekerjaan tetap bagi ibuibu di Kembangsongo. Hampir disetiap rumah ada yang menjadi buruh canting untuk membuat batik yang nantinya disetor kepada juragan atau konsumen yang memesan. Patut disayangkan bahwa para buruh canting tidak mengetahui proses selanjutnya, jadi para buruh canting hanya menerima upah nyanting yang relatif kecil dan banyak yang tidak tahu proses pewarnaan batik.

Perjalanan batik tulis terutama batik motif Nitik mengalami pasang surut dimana pengaruh kebudayaan lain, selera pasar/konsumen turut berperan besar terhadap perkembangan batik di sentra batik Kembangsongo. Ketidakmampuan pengrajin dalam menciptakan desaindesain baru batik Nitik menjadi penyebab utama, sehingga dalam kurun waktu 10 tahun terakhir ciri khas batik Nitik kurang diminati oleh konsumen batik tulis. Mereka enggan membuat desain baru kembali karena menunggu laku dijual, padahal mereka butuh uang cepat untuk mencukupi kebutuhan sehari-hari.

Terkait dengan hal tersebut, maka harus dilakukan kajian terhadapnya secara ilmiah melalui kegiatan penelitian untuk menghasilkan motif-motif batik Nitik baru yang memiliki cirri khas dan melakukan pendampingan yang kontinyu agar kreatifitas pembatik dalam inovasi desain baru tetap terjaga. Penelitian BOPTN ini menjadi salah satu jalan dalam rangka mengatasi permasalahan desain dan pewarnaan batik sesuai selera pasar dengan mengembangkan motif nitik yang menjadi cirri khas Kembangsongo. 


\section{HASIL DAN PEMBAHASAN}

Batik motif Nitik yang dibuat oleh pengrajin di sentra batik Kembangsongo, merupakan salah satu motif kekayaan batik Bantul, yang mendukung kegiatan ekonomi kreatif masyarakatnya. Dari kegiatan membatik yang dilakukan di sentra ini, telah melibatkan kaum ibu-ibu yang menjanjikan sebagai kegiatan industri yang menjadi lapangan pekerjaan tetap bagi ibuibu di Kembangsongo. Hampir di setiap rumah ada yang menjadi buruh canting untuk membuat batik yang nantinya disetor kepada juragan atau konsumen yang memesan. Patut disayangkan bahwa para buruh canting tidak mengetahui proses selanjutnya, jadi para buruh canting hanya menerima upah nyanting yang relatif kecil dan banyak yang tidak tahu proses pewarnaan batik.

Sentra batik tulis Nitik Kembangsongo yang terletak di Desa Jetis, Trimulyo, Bantul yang memiliki cirri khas motif batik yang disebut batik Nitik. Motif ini terdiri dari unsur titik-titik besar dan kecil membentuk suatu pola-pola geometris, bentuk-bentuk bunga, daun, sulur, dan garis-garis panjang. Motif batik Nitik ini sekarang dipandang oleh konsumen batik tulis terkesan monoton dan miskin inovasi bentuk dan hasil pewarnaan yang hanya berwarna biru wedel sogan coklat.

Keunikan yang dimiliki oleh sentra batik Kembangsongo dan ini tidak dimiliki oleh sentra batik tulis dimanapun adalah dengan membuat canting cawang. Canting ini sebenarnya canting yang digunakan untuk membatik tulis dengan ukuran klowong. Bedanya ialah pada ujung canting dibelah menjadi 4 sehingga hasil goresannya berbentuk garis bukan titik. Dari malam yang keluar pada bibir canting akan membentuk garis yang bisa membuat hasil cantingan memiliki cirri khas. Cirri khas inilah yang akhirnya disebut dengan Nitik sebagai penciri batik dari wilayah Kembangsongo. Walau demeikian para pembatik di Kembangsongo juga bisa membuat batik tulis dengan canting biasa dan hasilnya lebih baik dan halus.

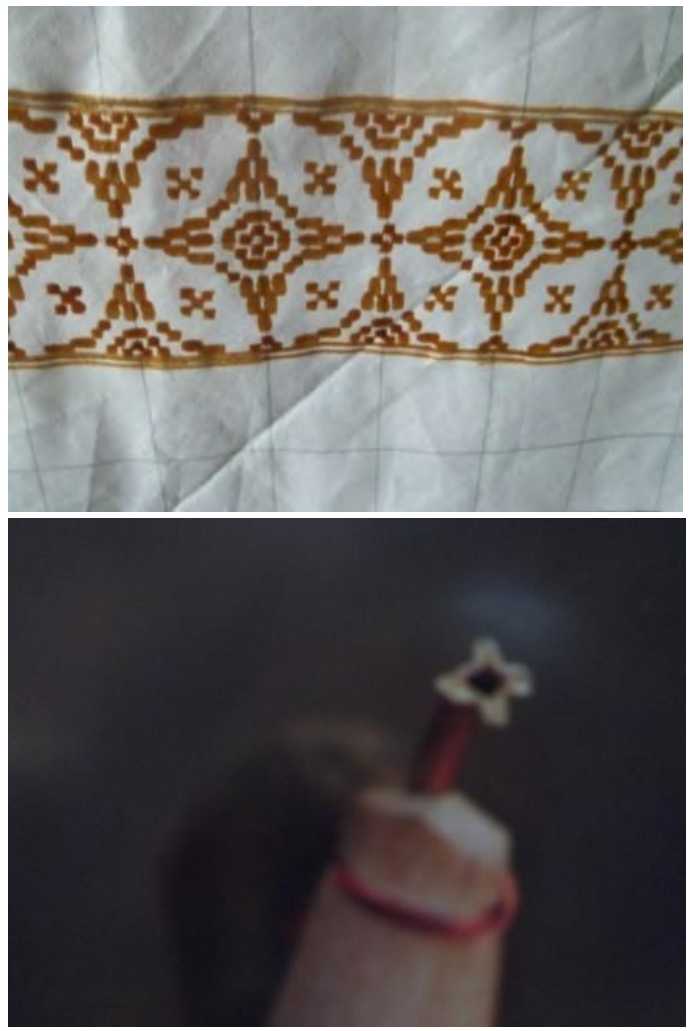

Gambar 1. Canting cawang dan hasil batikan dari canting cawang yang disebut nitik

Berikut beberapa motif khas batik Nitik yang menjadi kekayaan motif khas Kembangsongo dan saat ini masih diproduksi oleh masyarakat Kembangsongo: 

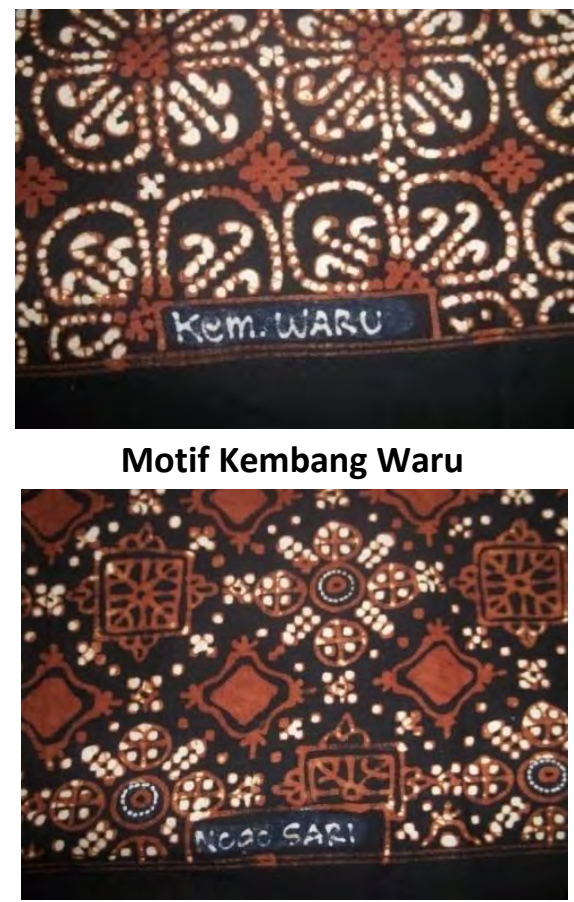

Motif Nogo Sari

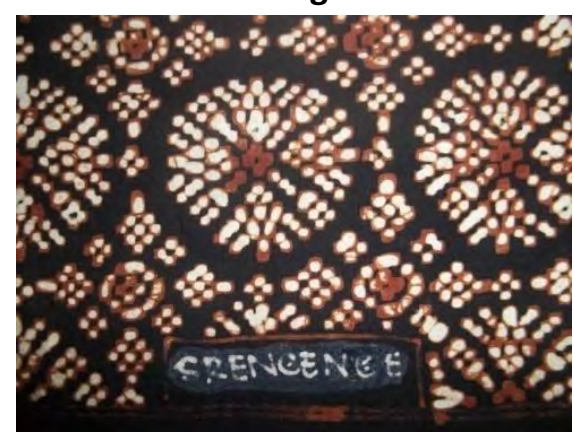

Motif Srengenge

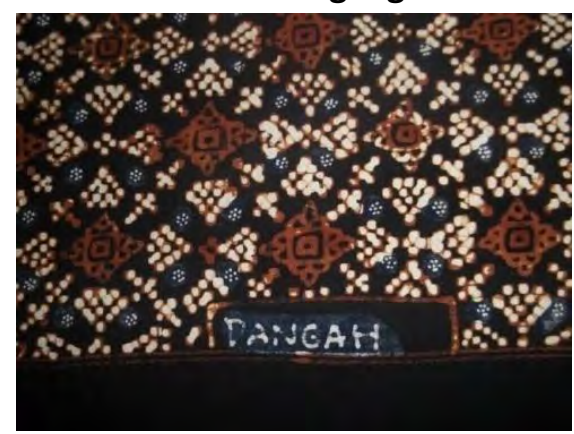

Motif Kembang Dangah

Batik di sentra Kembangsongo masih benar-benar dilakukan dengan teknik tulis sehingga hasilnya lebih rapi dan halus. Dari proses pemolaan/pemindahan pola pada kain, pencantingan, pewarnaan, sampai pada proses finishingnya dilakukan oleh kaum perempuan. Di sentra batik Kembangsongo ini terdapat dua kelompok pengrajin batik yaitu kelompok batik Sekar Nitik dan Sekar Sari dimana tiap kelompok terdiri dari 20-25 tenaga pembatik dan dipimpin oleh seorang ketua. Kelompok batik Sekar Nitik diketuai oleh ibu Aminah dan Kelompok batik Sekar Sari diketuai oleh ibu Dasilah.

Lingkungan pendidikan terutama pendidikan seni sangat ditunggu peran ilmiahnya dalam ikut melestarikan batik tulis tradisional seperti batik nitik.. Keterbatasan pengetahuan para pengrajin dalam hal desain dan mutu produk desain yang berpotensi pasar menjadi kendala nyata. Kendala ini sangat beralasan dimana para pengrajin batik di daerah Bantul merasa kesulitan membuat desain pengembangan yang berpotensi ekonomis dan sesuai dengan selera masyarakat modern yang melanda kehidupan masyarakat kita.

Imam Buchori Zaenudin (1986:8081) menegaskan bahwa desain bukan sekedar keterampilan dalam membuat barang, tetapi merupakan suatu proses berpikir secara sistematis untuk mencapai mutu yang lebih baik, meliputi mutu material, teknik, bentuk performasi, baik sebagian maupun secara keseluruhan. Pernyataan di atas menjadi terjawab apabila insan pendidikan seni turut ambil bagian sebagai wujud tanggung jawab dan pengabdian seni pada masyarakat. Untuk itu dibutuhkan langkah nyata dalam mengembangkan dan melestarikan batik tulis Nitik agar tetap eksis serta menjadi keunggulan industri kreatif bagi masyarakat di daerah Bantul. Sehingga 
produksi membatik yaitu batik motif Nitik dapat menjadi sumber penghasilan ekonomi bagi masyarakat Kembangsongo menuju pada kehidupan sejahtera dan berbudaya.

Melalui penelitian BOPTN peneliti mencoba untuk memberikan sumbangsih pemikiran ilmiah melalui pengembangan desain motif batik Nitik yang berbeda untuk memberikan warna kreasi dan inovasi yang lain. Tentunya pembuatan desain motif batik nitik baru yang dihasilkan melalui proses studi dan konsep penciptaan motif batik tidak dapat dijadikan suatu patokan akan laku dipasaran batik. Tetapi langkah ini ditempuh untuk memberikan stimulan atau semangat kreatifitas pengrajin dalam menciptakan diversifikasi produk dalam desain sehingga akan tercipta desaindesain baru batik dengan motif khas batik nitik di Kabupaten Bantul. Dengan terciptanya desain baru yang tetap menonjolkan ciri khas batik nitik tersebut akan tetap memberikan hasil positif bagi pencitraan batik Bantul yang tidak dimiliki oleh penghasil batik tulis serupa.

Pembuatan batik tradisional terdapat empat aspek yang harus diperhatikan, yakni motif, warna, teknik pembuatan dan fungsinya. Batik memiliki keindahan visual karena semua ornamen, isian dalam pola tersusun dengan rapi dan harmonis. Batik juga memiliki keindahan spiritual karena pesan, harapan, ajaran hidup, dan doa kepada Tuhan Yang Maha Esa dari pembuat batik dituangkan dalam pola batik (Sariyatun, 2005:3). Ragam hias batik merupakan ekspresi keadaan diri dan lingkungan budaya penciptanya.
Pengembangan batik tulis nitik yang telah dilakukan oleh peneliti merunut pada batik tradisional dimana keberadaan batik tulis menjadi tolok ukur. Hal ini ditempuh untuk menghasilkan batik yang halus dengan teknik pembatikan yang baik pula. Teknik pewarnaan juga menggunakan pewarna sintetis naptol yang lebih kuat dan berdaya tahan lama dengan didukung kain mori primissima yang halus. Tahapan desain menjadi tahapan panjang yang harus dilakukan karena harus mendata ulang tentang motif khas batik nitik yang hampir memiliki kesamaan bentuk dan warna yang monoton.

Data motif batik nitik terkumpul dari berbagai sumber literature dan dari pendataan di lapangan, maka proses selanjutnya melakukan pembuatan desaindesain alternatif yang kemudian dipilih beberapa desain terpilih. Desain-desain terpilih inilah yang menjadi bahan utama untuk dibuat pada produk batik dengan ukuran $40 \times 40 \mathrm{~cm}$ sebanyak 10 desain dan akan diwujudkan pada kain panjang sejumlah 7 batik kain panjang. Selanjutnya dilakukan pembuatan desain-desain yang akan dijadikan master untuk pembuatan batik nitik dengan desain baru.

Proses pembuatan desain dilakukan dengan membuat sket-sket alternative dari hasil pendataan motifmotif batik nitik yang sudah tercipta. Setelah menemukan desain dan tertuang pada kertas, selanjutnya dibuat detailnya dari desain yang telah terpilih. Desain terpilih tersebut selanjutnya diberi warna dan akan menjadi master yang menjadi dasar pembuatan batik pada kain panjang. Berikut 10 desain yang tercipta yang menjadi master desain batik nitik baru. 


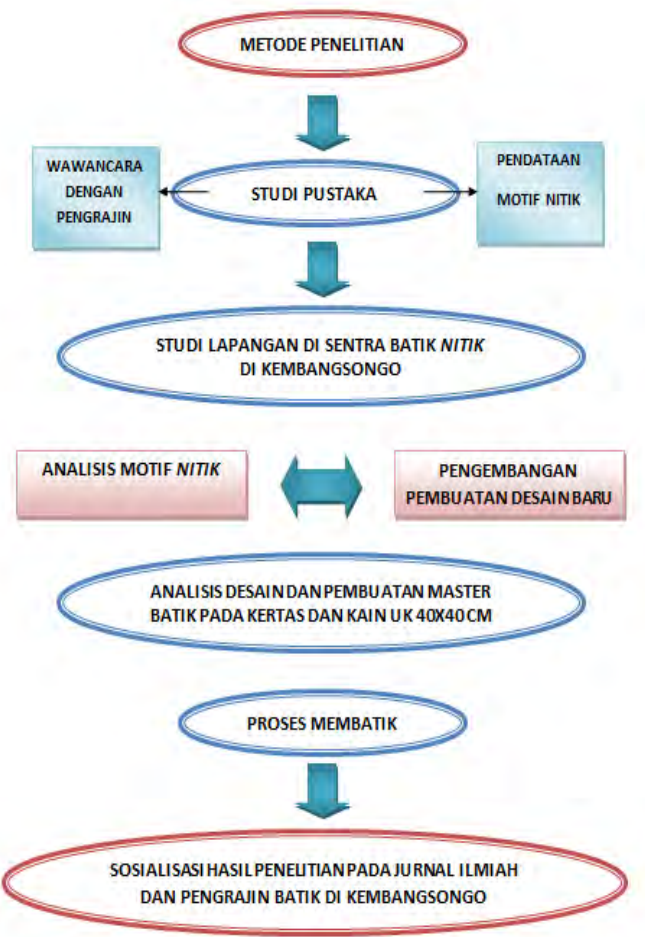

Berikut beberapa desain yang telah dihasilkan dengan mengembangkan motif batik nitik yang diwarna baru disesuaikan dengan warna yang lebih cerah sesuai selera masyarakat sekarang:
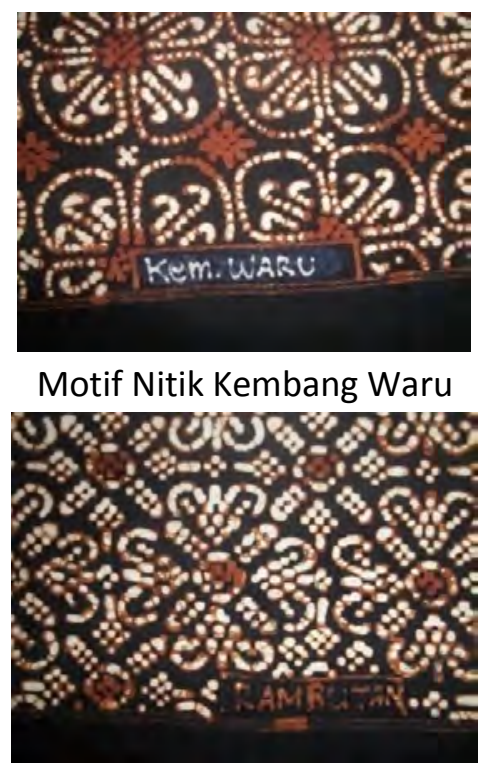

Motif Nitik Rambutan

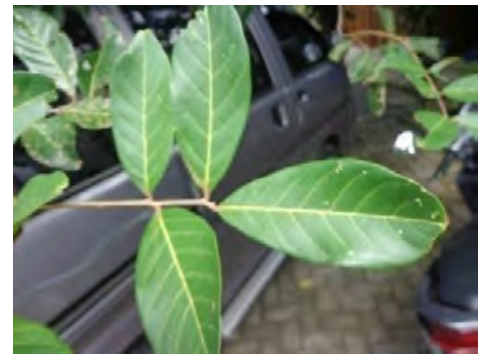

Daun Rambutan

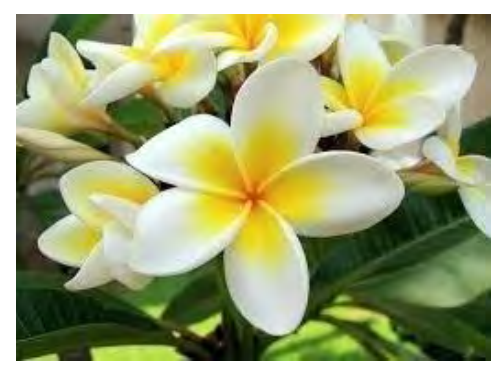

Bunga Kamboja

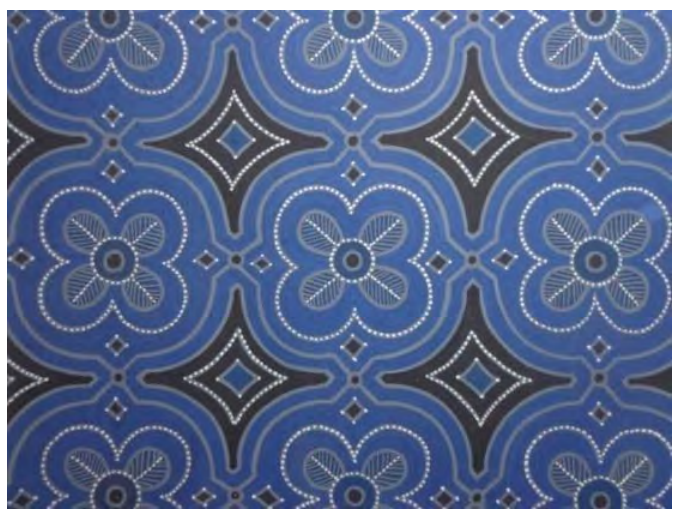

Gambar 2.Ceplok Kamboja

Desain batik nitik baru 1 (pengembangan nitik kembang waru + rambutan + daun kamboja

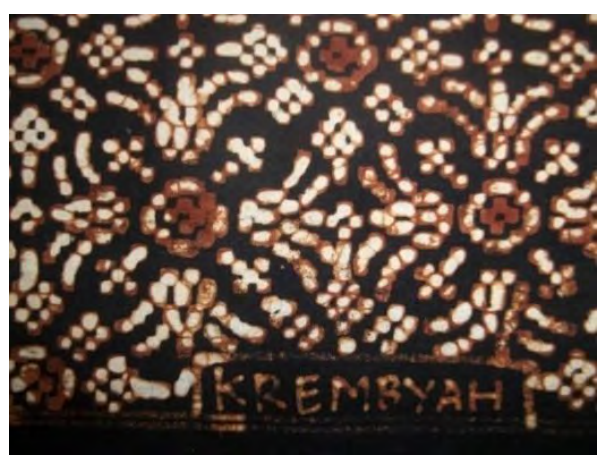

Motif Nitik Krembyah 

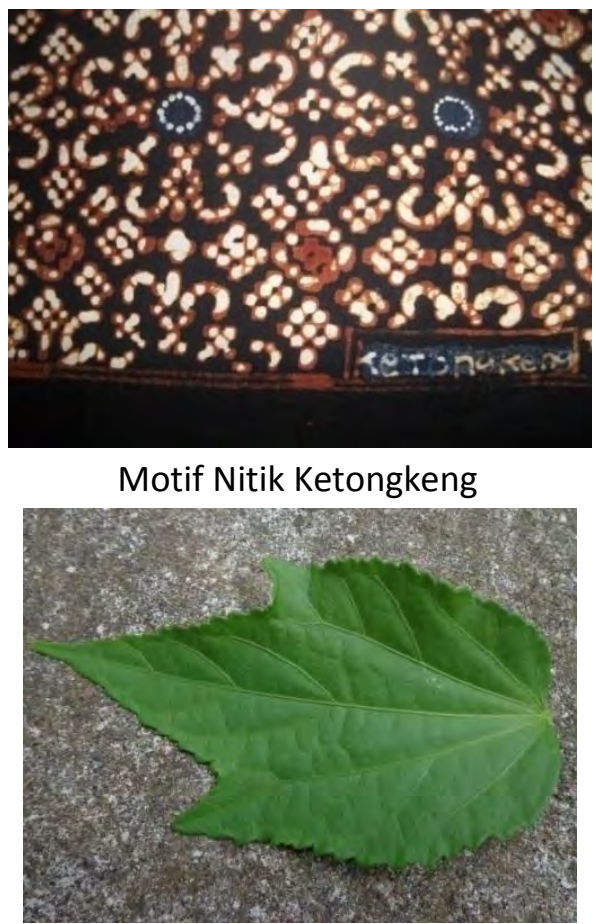

Daun Kembang Sepatu

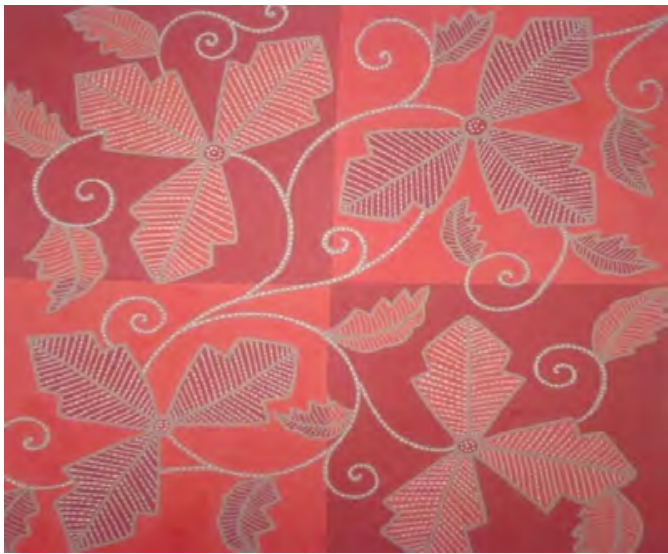

Gambar 3. Lung Godhong Sepatu

Desain batik nitik baru 1 (pengembangan nitik krembyah + ketongkeng + daun kembang sepatu)

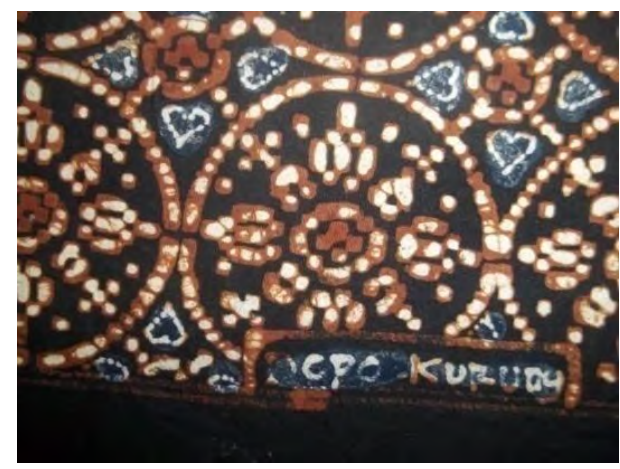

Motif Nitik Dopo Kurung
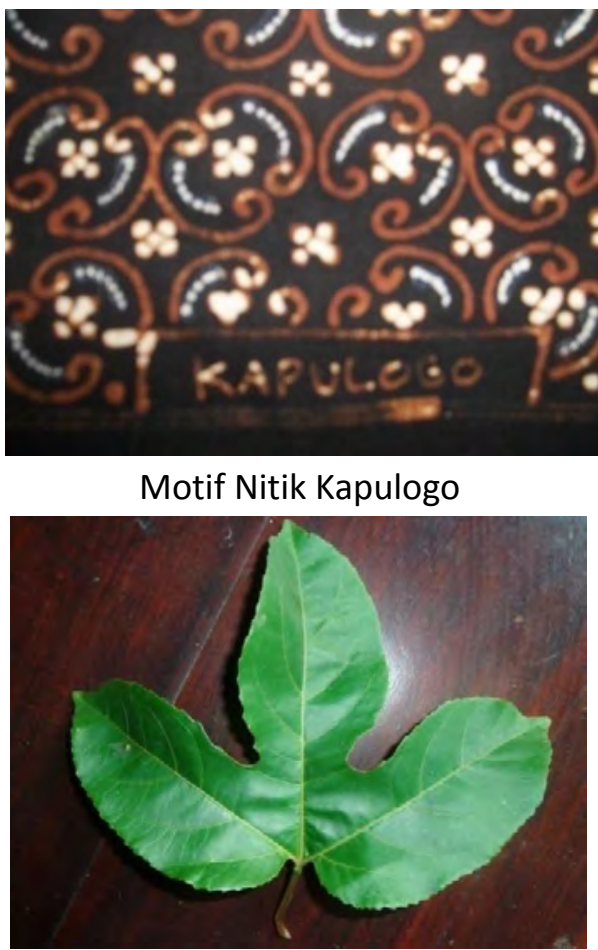

Daun Markisa

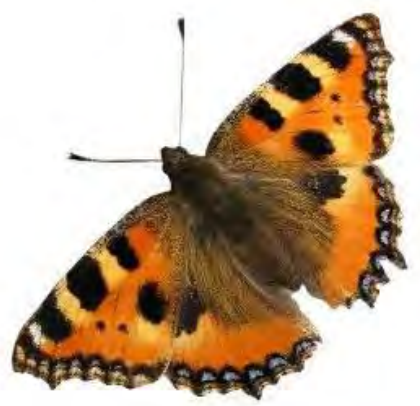

Kupu-kupu

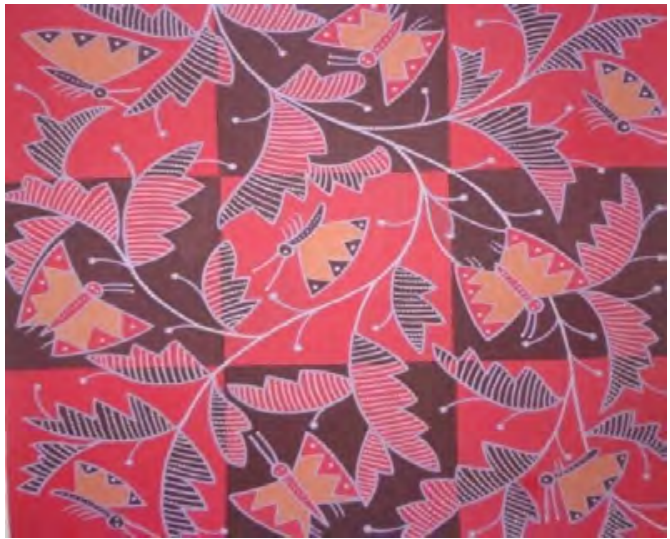

Gambar 4. Lung Kupu-Kupu

Desain batik nitik baru 1 (pengembangan nitik dopo kurung + kapulogo + daun markisa + kupu-kupu) 


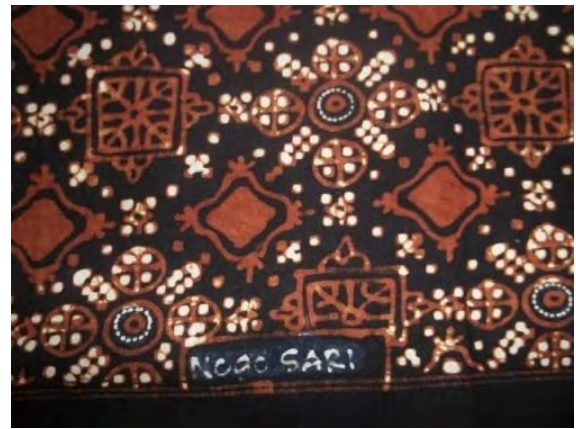

Motif Nitik Nogo Sari

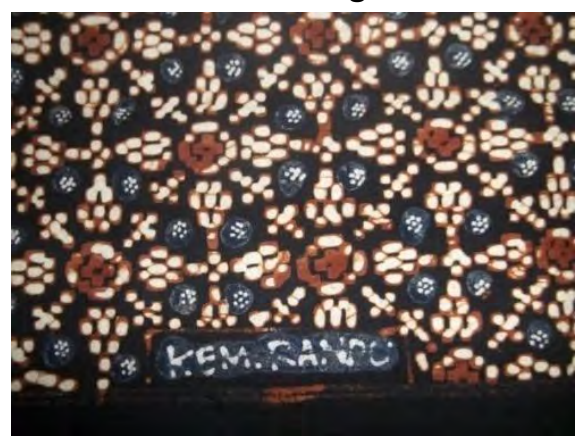

Motif Nitik Kembang Randu

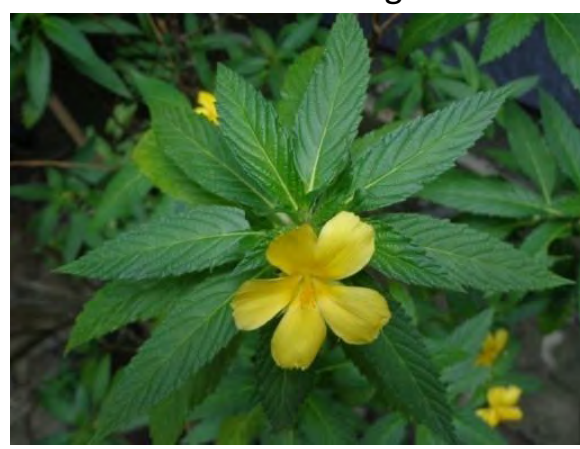

Bunga Bintang

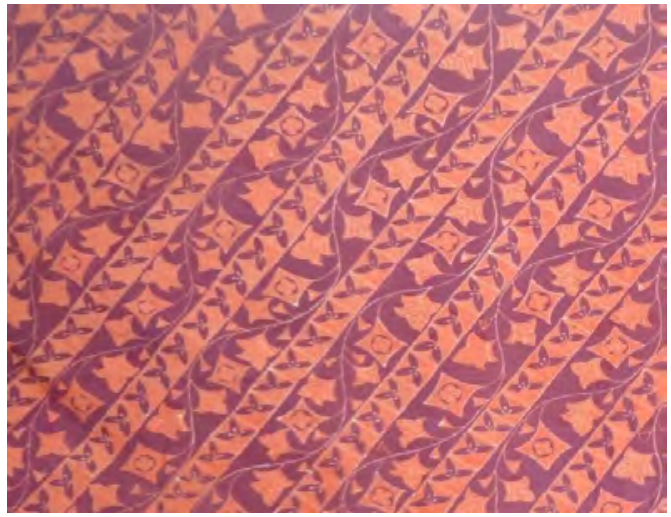

Gambar 5. Lung Kembang Bintang

Desain batik nitik baru 1 (pengembangan nitik nogo sari + kembang waru + bunga bintang)

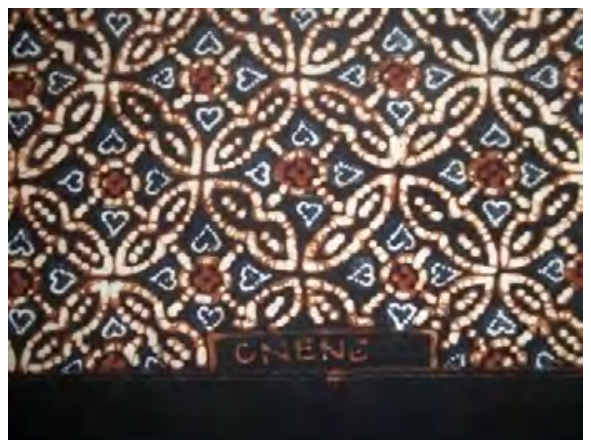

Motif Nitik Oneng

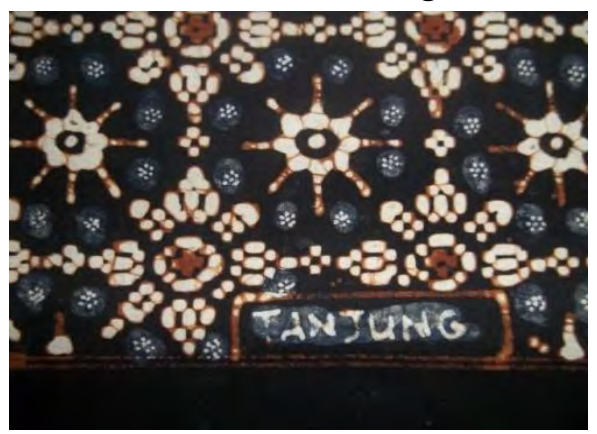

Motif Nitik Tanjung

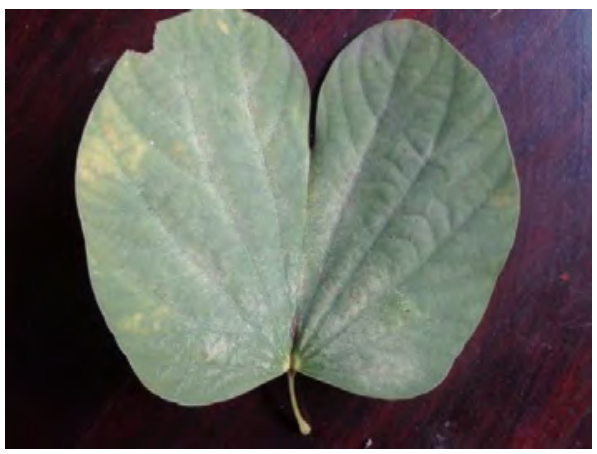

Daun Merak Dampit

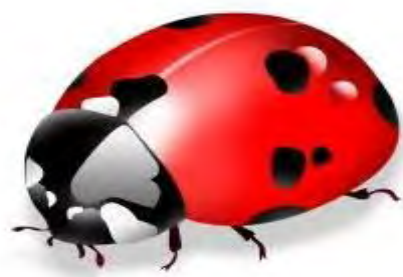

binatang Kepik 


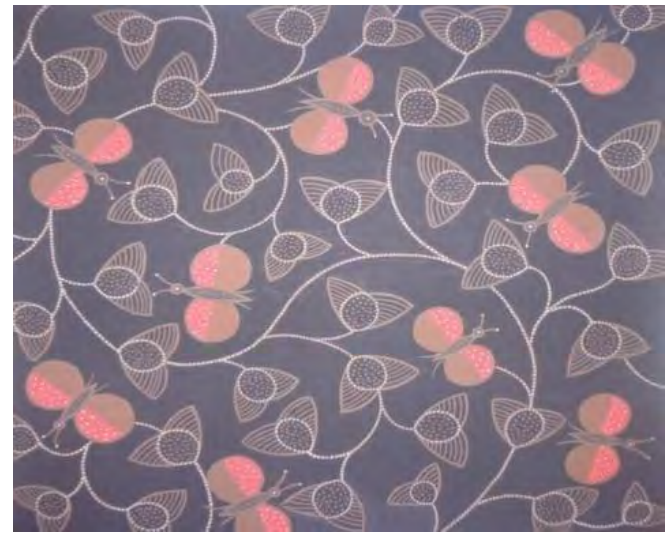

Gambar 6. Lung Daun Kembar

Desain batik nitik baru 1 (pengembangan nitik oneng + tanjung + daun merak dampit + kepik)

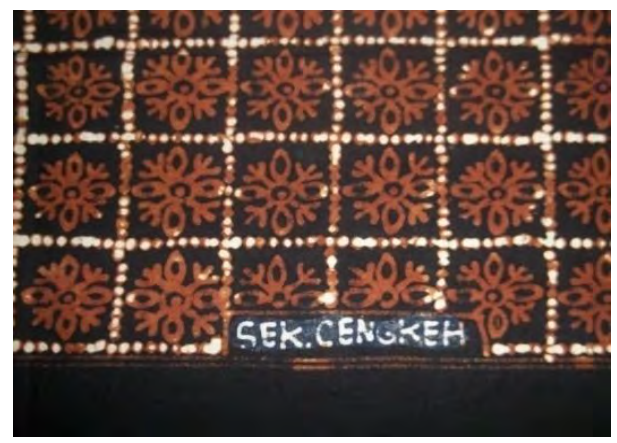

Motif Nitik Cengkeh

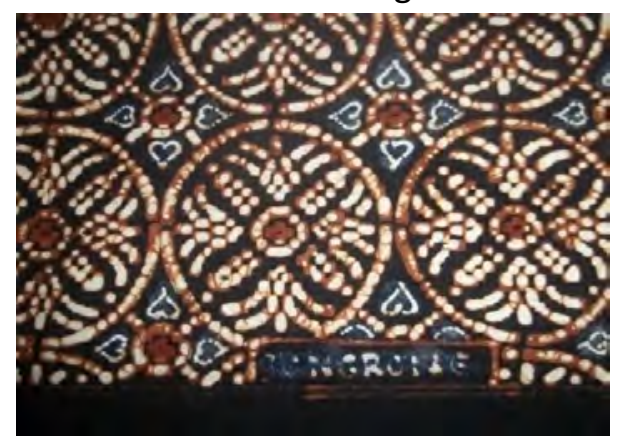

Motif Nitik Tongrong

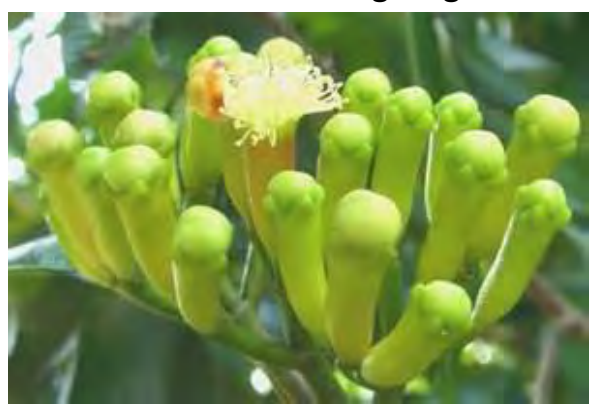

Bunga Cengkeh

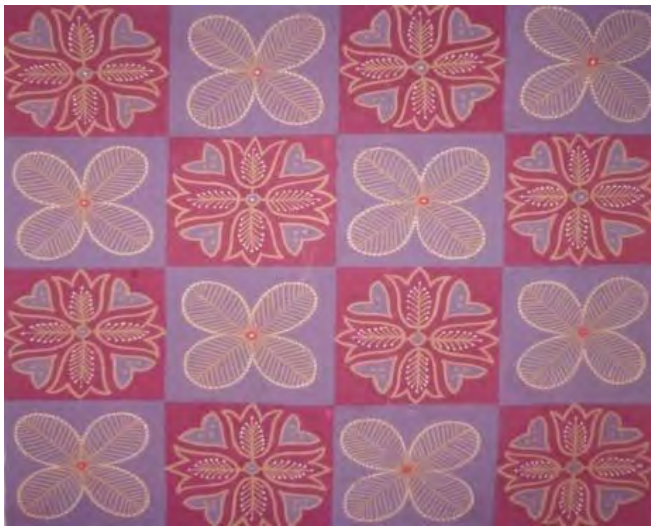

Gambar 7. Lung Kembang Cengkeh

Desain batik nitik baru 1 (pengembangan nitik cengkeh + tongrong + bunga cengkeh)

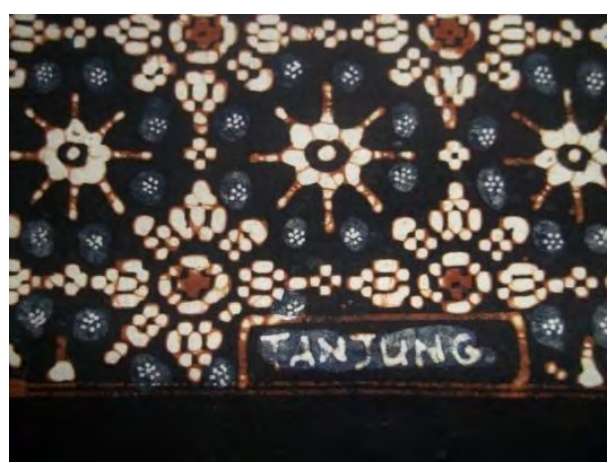

Motif Nitik Tanjung

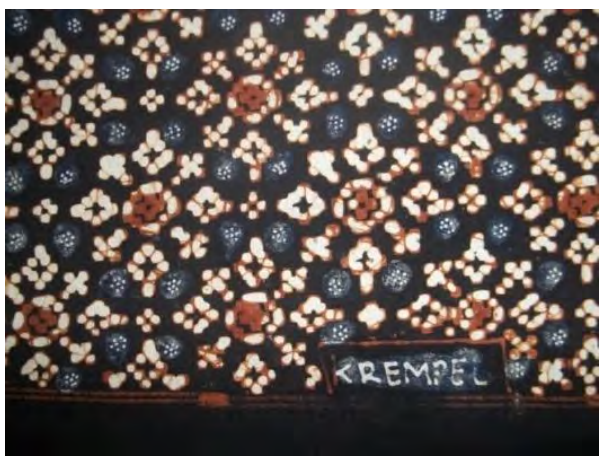

Motif Nitik Krempel

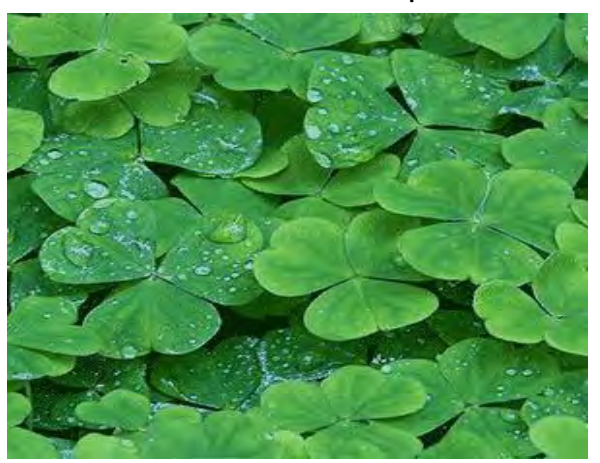

Daun Semanggi 


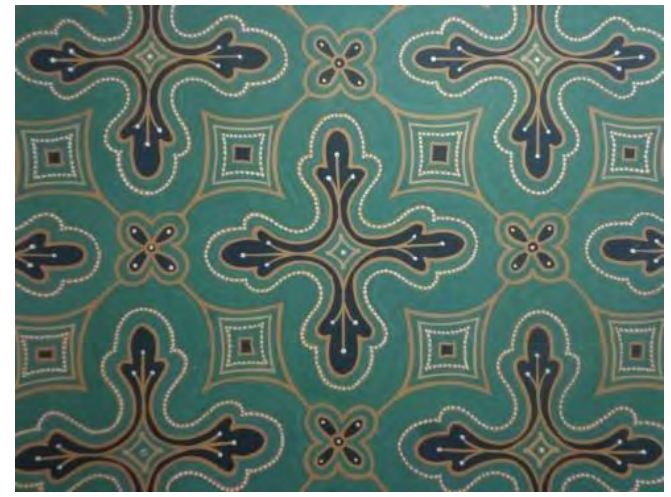

Gambar 8. Ceplok Semanggi

Desain batik nitik baru 1 (pengembangan nitik tanjung + krempel + daun semanggi)

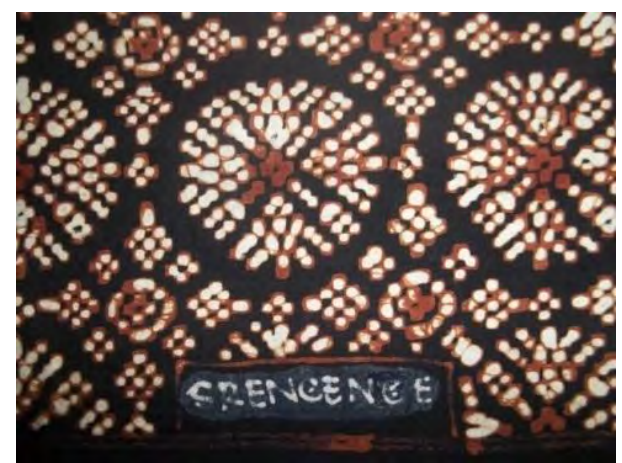

Motif Nitik Srengenge

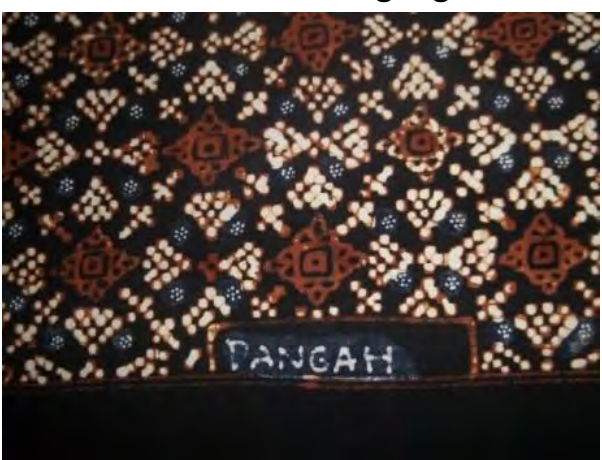

Motif Kembang Dangah

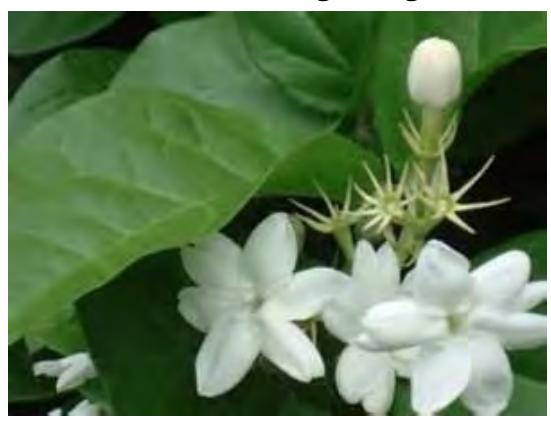

Bunga melati

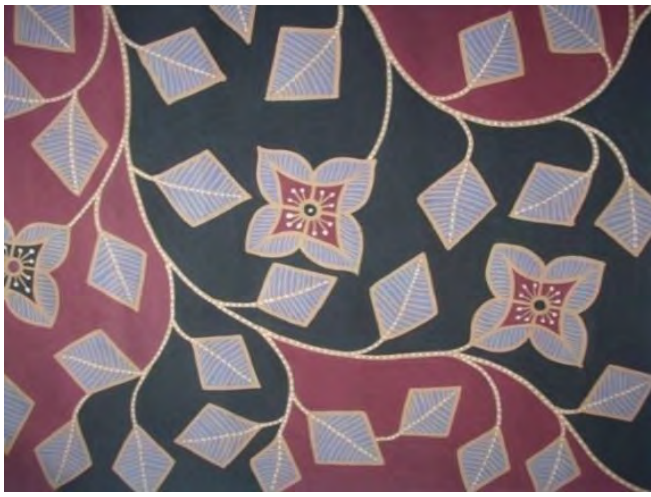

Gambar 9. Lung Kembang Melati

Desain batik nitik baru 1 (pengembangan nitik

srengenge + dangah + daun bunga melati)

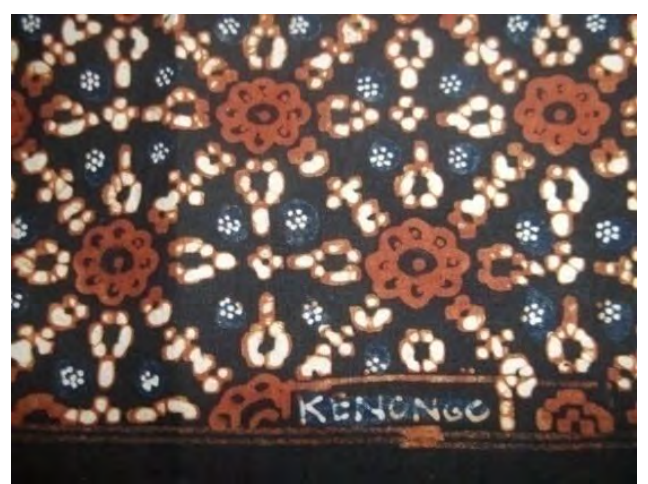

Motif Nitik Kenongo

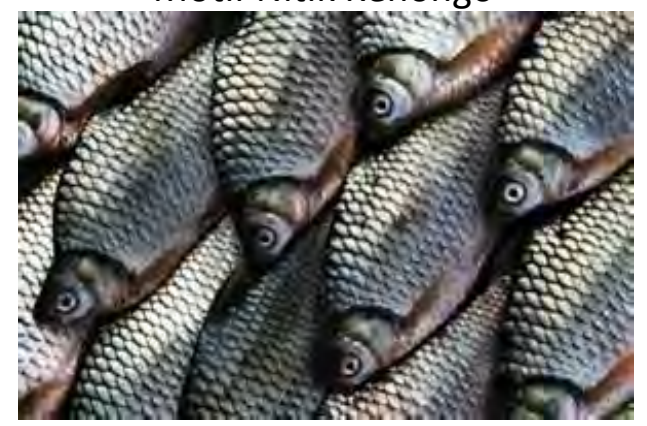

Iwak kali

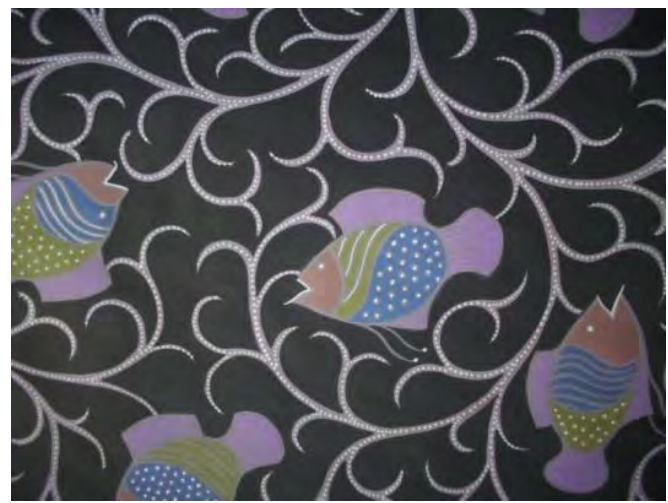

Gambar 10. Lung Iwak Kali

Desain batik nitik baru 1 (pengembangan nitik

kenongo + iwak kali) 

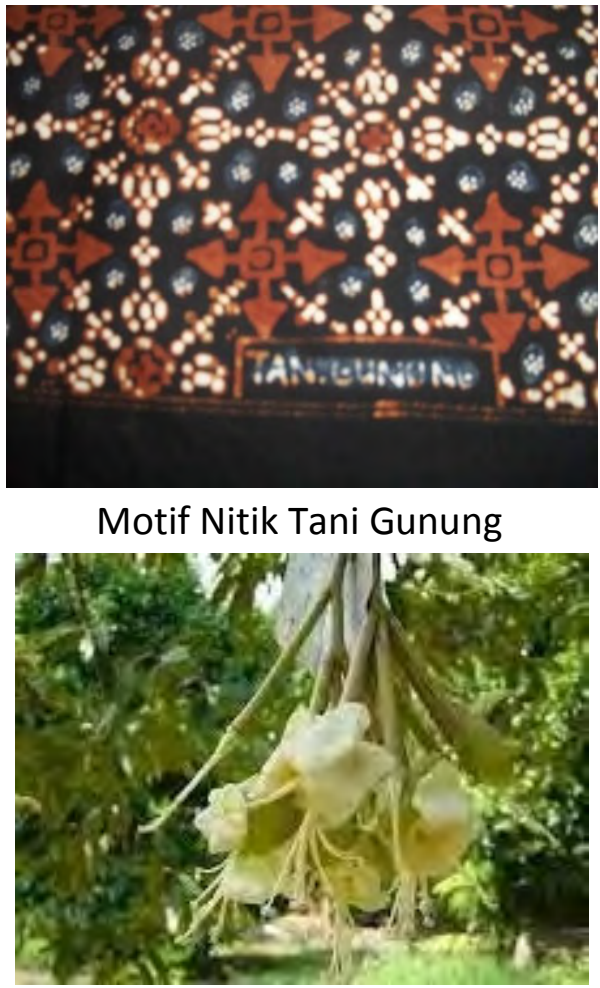

Bunga Duren

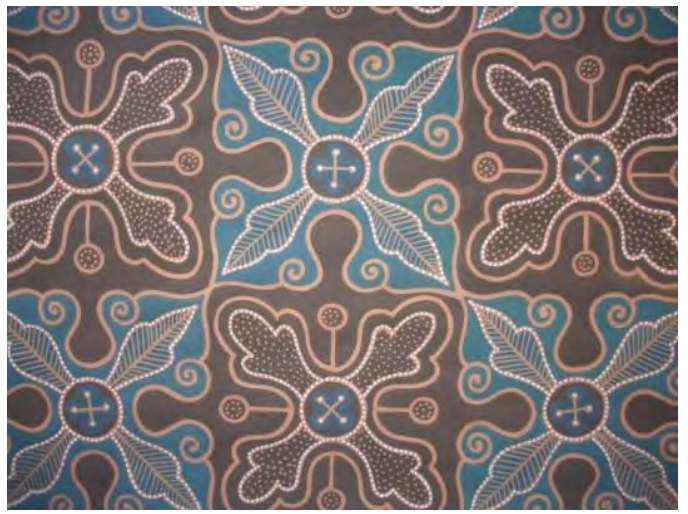

Gambar 11. Ceplok Kembang Duren

Desain batik nitik baru 1 (pengembangan nitik tani gunung + bunga durian)

Desain yang telah tercipta kemudian dipindah ke kain untuk dilakukan pemolaan dan proses pencantingan malam. Pencantingan malam dilakukan oleh mahasiswa tekstile ISI Yogyakarta yang tergabung dalam tim penelitian. Tujuannya agar mahasiswa juga mengetahui perjalanan penelitian dari membuat proposal, proses penelitian, pembuatan master desain sampai pada finalisasi pembuatan produk jadi sebagai output penelitian BOPTN ini. Setelah proses pencantingan malam jadi, proses selanjutnya proses pewarnaan kain. Pada kesempatan penelitian ini kita menggunakan zat warna kimia dengan menggunakan warna naptol dan indigosol.

Proses yang dilalui dari tahapantahapan kerja penelitian telah dapat dilalui dengan baik. Prioritas out put penelitian adalah menciptakan batik dengan mengembangkan motif nitik yang mirip dengan teknik riningan. Dalam menciptakan hasil cantingan yang baik, maka teknik batik dengan membuat titik-titik (cecekan) atau riningan, sehingga batik yang tercipta dengan teknik batik tulis yang halus. Dengan harapan teknik kombinasi dengan canting nitik dan canting cecek dapat dicapai untuk memperoleh hasil batik yang baik pula.

\section{PENUTUP}

Seni tradisional adalah kesenian asli yang lahir dengan adanya dorongan emosi dan kehidupan batin yang murni atas dasar pandangan hidup dan kepentingan pribadi masyarakat pendukungnya. Perkembangannya tergantung pada kondisi sosial budaya setempat dan persentuhan dengan masyarakat pendukung, serta pengaruh lingkungannya. Membatik di sentra 
Kembangsongo merupakan kegiatan produktif yang dilakukan sebagian masyarakat sebagai sumber mata pencaharian. Kegiatan membatik di sentra Kembangsongo lebih dinamis akan tetapi teknik pewarnaan masih monoton dan bahkan para pengrajin jarang melakukan pewarnaan sendiri.

Dengan menggali sumbersumber tradisi yang kaya dapat tercipta produk kreatif dengan pesona estetis yang kuat dan memiliki identitas yang memperlihatkan aspek-aspek budaya lokal. Kontribusi positif disiplin ilmiah dari lembaga pendidikan seni terutama dari segi wacana adalah memberikan orientasi, arahan pada perkembangan dan perubahan yang berlangsung di dalam masyarakat, khususnya menyangkut aspek-aspek desain, budaya visual dan kebudayaan. Desain sebagai salah satu aspek dari hasil produksi merupakan suatu kesatuan yang mengandung berbagai unsur, seperti bentuk, warna, ukuran, fungsi, teksture, dan pengerjaan dari suatu produk.

Seni batik nitik sebagai salah satu local genius sangat memegang peranan penting. Demikian pentingnya sehingga harus ada kesadaran yang melekat dimana kepeduliaan masyarakat penyangga seni batik untuk melakukan revitalisasi atau pengembangan desain. Revitalisasi ini harus mendapat perhatian yang saling terkoordinasi antara masyarakat, lembaga pendidikan, dan pemerintah setempat. Seni batik nitik memegang peranan sentral, yang eksistensinya merupakan roh atau spirit yang telah ikut menentukan warna kepribadian masyarakatnya. Batik yang telah berhasil diciptakan dalam penelitian ini diharapkan mampu menjadi tonggak dasar penyadaran tersebut. Agar masyarakat peduli dan mau menjadikan batik sebagai kebutuhan sandang yang terbukti mampu menyesuaikan dengan perubahan zamannya dan tidak hanya menjadi kebanggaan semata.

\section{DAFTAR PUSTAKA}

Djomena, Nian S., (1990), Batik dan Mitra, Penerbit Djambatan, Jakarta

Doellah, Santoso, (2002), Batik Pengaruh Zaman dan Lingkungan, Danar Hadi, Surakarta

Elliot, Inger McCabe, (2004), Batik Fabled Cloth of Java, Published by Periplus Edition, Singapore

Herusatoto, Budiono, 2001, Simbolisme Dalam Budaya Jawa, Hanindita Graha Widia, Yogyakarta

Kamajaya, 1985, Serat Centhini (Suluk Tambangraras) Yasandalem Kanjeng Gusti Adipati Anom Mangkunegara (Ingkang Sinuwun Paku Buwana $V$ ing Surakarta) Transliterasi latin, Yayasan Centhini, Yogyakarta 
Koentjaraningrat, 1987, Kebudayaan, Mentalitas dan Pembangunan, Gramedia, Jakarta

Nurdjanti, Nunung, 2006, Jaringan Makna Tradisi Hingga Kontemporer, Kenangan Purna Bakti untuk Prof. Soedarso SP., M.A., BP ISI Yogyakarta

Padmapoespita, K.J., 1966, Pararaton, Penerbit Taman Siswa, Yogyakarta

Ronald, Arya, 2005, Nilai-nilai Arsitektur Rumah Tradisional Jawa, Gadjah Mada University Press, Yogyakarta

Sariyatun, 2005, Usaha Batik Masyarakat Cina Di Vorstenlanden Surakarta Awal Abad XX, Sebelas Maret University Press, Surakarta

Setiawati, Puspita, 2004, Kupas Tuntas Teknik Proses Membatik, Penerbit Absolut, Yogyakarta

Sukanadi, I Made \& Arif Suharson, 2012, Batik Mbantulan Di Sentra Batik Giriloyo Dan Wijirejo Bantul, Laporan Penelitaian Hibah Bersaing, LPT ISI Yogyakarta 2012

Susanto, Sewan, 1973, Seni Kerajinan Batik Indonesia, Balai Penelitian Batik dan Kerajinan, Lembaga Penelitian Pendidikan Industri, Departeman Perindustrian RI, Jakarta

Suyanto, 1992, Tata Warna dan Teknik Pembuatan Batik Tradisional, Makalah disampaikan dalam Seminar Batik Tradisional Indonesia tanggal 6 Agustus 1992, STSI Surakarta

Tambunan, Tulus T.H., 2002, Usaha Kecil dan Menengah di Indonesia:
Beberapa Isu Penting, Salemba Empat, Yogyakarta

Riyantono, dkk (Tim Peyusun), 2010, Batik Bantul, Pemerintah Daerah Kabupaten Bantul, Bantul

Van Der Hoop, A.N.J. a Th., 1949, Indonesische Siermotieven (Ragam-ragam Perhiasan Indonesia), Koninklijk Bataviaasch Genootschap Van, Kunsren En Wetenschappen

Zaenudin, Imam Buchori, 1986, Peranan Desain Dalam Peningkatan Mutu Produk, dalam Paradigma Desain Indonesia, Rajawali, Bandung

\section{LAMPIRAN}

Hasil Realisasi Penelitian Batik Kain Panjang Dari Pengembangan Motif-Motif Nitik Kembangsongo

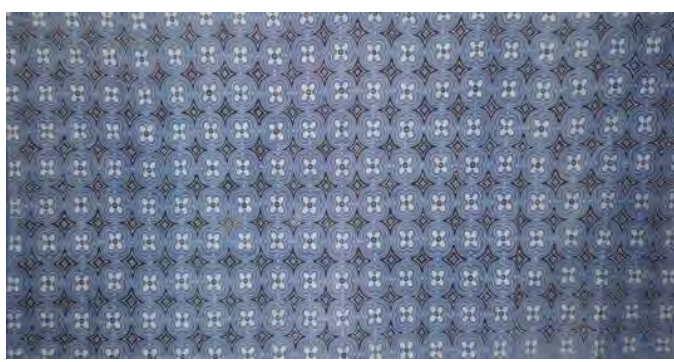

Batik Kain Panjang "Ceplok Kamboja”

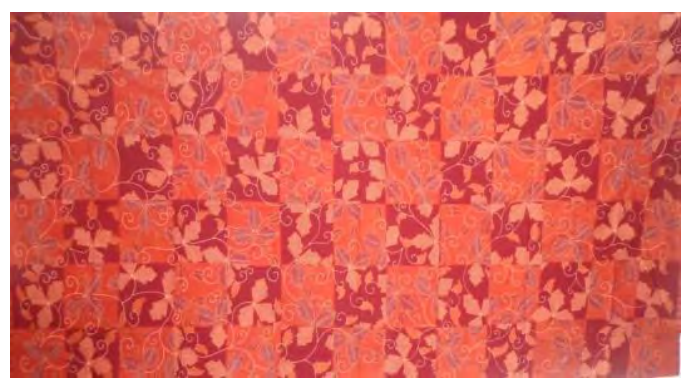

Batik Kain Panjang " Lung Godhong Kembang Sepatu" 


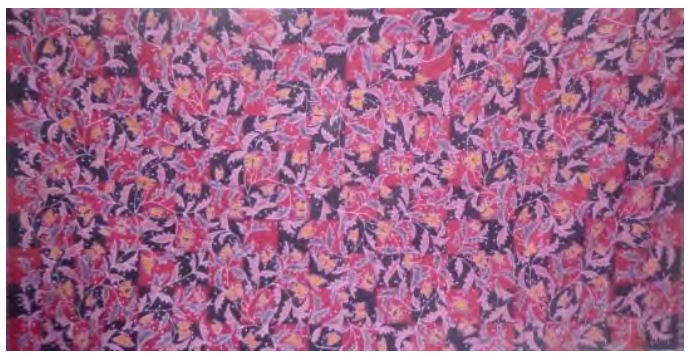

Batik Kain Panjang "Lung Kupu-Kupu”

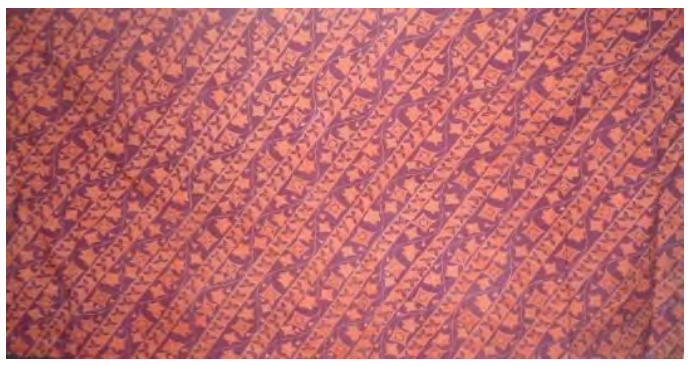

Batik Kain Panjang “ Lung Kembang Bintang"

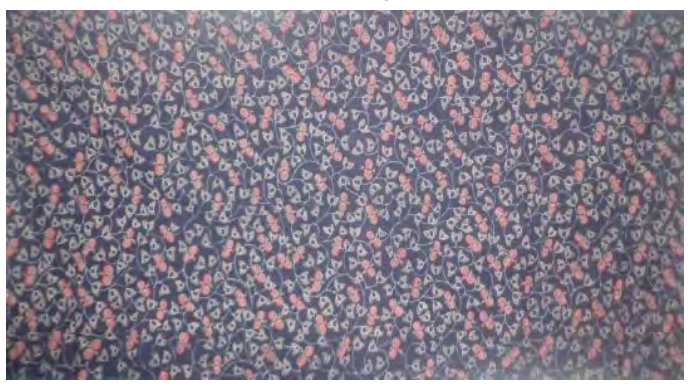

Batik Kain Panjang "Lung Daun Kembar"

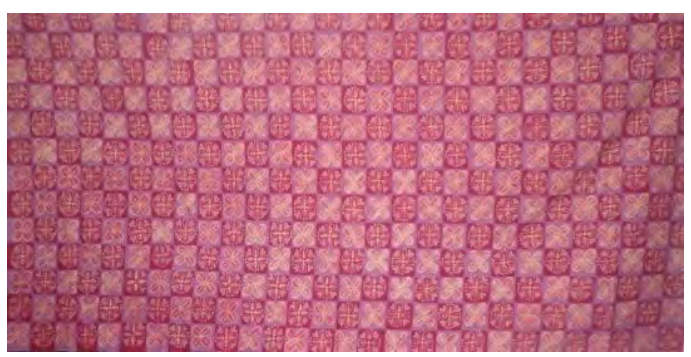

Batik Kain Panjang " Ceplok Kembang Cengkeh"

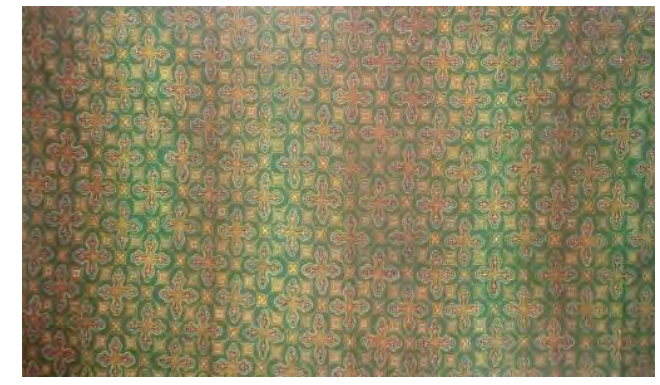

Batik Kain Panjang "Ceplok Semanggi" 